\title{
0 memorial dos lanceiros negros: disputas simbólicas, configurações de identidades e relações interétnicas no Sul do B rasil
}

\author{
Ana Paula Comin de Carvalho*
}

\begin{abstract}
R esumo: Tomando como universo empírico um evento em prol da construção de um memorial em homenagem aos lanceiros negros no município de Pinheiro Machado (RS), atento para as disputas simbólicas que se travam en tomo dessas figuras. Procuro demonstrar que as diferentes apropriaçães de uma experiência histórica comm - o Massacre de Porongos - têm conexões com a configuração de identidades étnicas e regionais e com as relações entre os diversos grupos sociais que compõem o estado do Rio Grande do Sul.

Palavr as-chave: lanceiros negros; identidade étnica; identidade regional.
\end{abstract}

0 objetivo do presente artigo é, com base na análise de um evento em prol da construção de um memorial em homenagem aos lanceiros negros no município dePinheiro M achado (RS), ${ }^{1}$ fazer al gumas considerações sobre as disputas simbólicas que se travam em torno dessas figuras. Trata-se de compreender como diversos

\footnotetext{
*Doutoranda em Antropologia Social pela UFRGS.

1. Pinheiro $M$ achado é um dos municípios mais antigos do Rio Grande do Sul. A té 1830 , a sua área pertencia a Rio Grande. Depois passou a integrar a cidade de Piratini, desmembrando-se em 24 de fevereiro de 1879, sob a denominação de Nossa Senhora da Luz das Cacimbinhas. A povoação desse município, segundo registros, iniciou-se pelo brigadeiro Rafael Pinto Bandeira, por volta de 1765. Os primeiros habitantes foram os açorianos Thomaz A ntônio de Oliveira e J osé Dutra de A ndrade, que receberam sesmarias na Coxilha do Velleda, em 1790. Segundo a lenda, Dutra de Andrade teria perdido a visão e feito uma promessa. Se ele a recuperasse ao lavar os ol hos nas águas das cacimbinhas, mandaria construir uma capela em honra de Nossa Senhora da Luz. 0 milagre teria ocorrido. Depois da capela, foi criado um curato em 1851. Em 1857, foi elevada a freguesia e em 1878 ocorreu a emancipação. 0 município de Cacimbinhas teve seu nome mudado para Pinheiro Machado no governo do intendente provisório Ney Lima Costa, quando 0 senador José Gomes Pinheiro $M$ achado foi assassinado no Rio de Janeiro, por Mânsio de Paiva, que era um morador da região de Cacimbinhas. A mudança de nome não foi aceita pela população, que se rebelou contra 0 intendente, forçando-o a deixar a cidade.
}

setores se apossam de uma experiência histórica comum de forma diferenciada. Parte-se do pressuposto que essas apropriações contemporâneas de um episódio passado estão intimamente relacionadas com a configuração de identidades étnicas e regionais e com as relações entre os diferentes grupos formadores do Rio Grande do Sul. A ntes disso, contudo, entendo ser necessário familiarizar o leitor com o contexto com base na qual emerge essa questão.

Os gaúchos compartilham experiências históricas marcantes que são constitutivas de seus modos de imaginação, cognição e ação, bem como de sua identidade regional (Grimson, 2003). Os conflitos bélicos nos quais a região e seus habitantes estiveram envolvidos são eventos que são constantemente evocados para fal ar do espírito livre e combativo do povo do Rio Grande do Sul. Dentre eles, a R evolução Farroupilha é, com toda a certeza, o mais lembrado. Ela é representada pelos movimentos regiona-

2. Segundo Flores, "a Revolução Farroupilha faz parte dos movimentos liberais que abalaram o Império do Brasil no período regencial, quando explodiram dissensões políticas entre os liberais federalistas e os conservadores unitários nas províncias do Ceará (1831-1832), Pernambuco (1831- 
listas como um momento marcante de nossa história, um episódio de bravura que resultou em uma separação temporária do RS do restante do Brasil. Essa guerra que durou dez anos é relacionada com a imagem do gaúcho como guerreiro valente e heróico que tem nesse conflito o pano de fundo para as suas façanhas. Dessa forma, configura-se como uma referência para a exaltação dessa figura, ou seja, a menção aos heróis farroupilhas se insere na lógica de construção desse tipo social a ser cultuado (Brum, 2004). Além disso, é em torno desse episódio que se estabelece simbolicamente a relação do gaúcho com o restante do país, seja para afirmar o seu caráter autônomo, seja para evidenciar que ele é brasileiro por opção (Barcellos, 1997; Oliven, 1986 e 1990) Todos os anos, em vários municípios do estado, são realizados cerimônias, desfiles, acampamentos e comemorações em tributo à memória dessa guerra. ${ }^{3}$ Esses eventos são promovidos por prefeituras, governo do estado e pelos movimentos regionalistas.

A conformação da imagem do gaúcho sublinha a presença luso-brasileira no $\mathrm{R}$ io $\mathrm{Grande}$ do Sul e o valor da imigração européia e simultaneamente omite a presença do negro ( $\mathrm{Bar}$ cellos, 1996). Como observa M aciel (1994), a construção da nossa identidade regional passa por cima das mais diversas clivagens de ordem social, econômica, étnica e cultural, operando com a idéia da existência de uma homogeneidade. A inda que se distinga da configuração do povo brasileiro, essa "fábula regional" não prescinde da ideologia da mestiçagem nas situações em que se torna impossível ignorar a presença dos negros na região. A elaboração do imaginário gaúcho sobre si mesmo exclui 0 negro dos estudos históricos e da própria sociedade (B arcellos, 1996).

1835), M inas Gerais (1833-1835), Grão-Pará (1835-1840), B ahia (1837-1838), M aranhão (1838-1841) e Rio Grande do Sul (1835-1845)" (2004, p. 25). É chamada de revolução porque implicou a mudança de governo com a instituição do sistema republicano, mas, de acordo com o autor trata-se de uma guerra civil entre aqueles que aderiram ao movimento e os que não o fizeram.

3. Como observa M aciel (1999), as representações associadas ao gaúcho construídas pelo tradicionalismo foram gradativamente adotadas pelo poder público, estabelecendo-se como "oficiais". U ma análise mais aprofundada desse processo pode ser encontrada em Oliven (1991).
A pesar de omitidos pela maior parte da historiografia tradicional, os negros desempenharam papel fundamental para as forças rebeldes farroupilhas durante o conflito com 0 Império. Estima-se que eles tenham, durante essa revolução, composto de um terço à metade do exército rebelde (L eitman, 1997, p. 61-78). Eles foram integrados às fileiras farroupil has em duas divisões, uma de cavalaria e outra de infantaria, criadas respectivamente em 12 de setembro de 1836 e em 31 de agosto de 1838, denominadas de Corpos de L anceiros N egros, sendo compostas por negros livres e escravos libertados pela República sob a promessa de lutarem nas fileiras de seu exército (Carrion, 2003, p. 6-7). A ntes mesmo da criação desses corpos, os negros já haviam desempenhado destacado papel em conflitos como a tomada de Porto A legre, em setembro de 1835, e de Pelotas, em abril do ano seguinte. $N$ egros livres e alforriados, juntamente com índios, mestiços e escravos fugidos do U ruguai contribuíram com a causa farroupi Iha não somente como soldados, mas também trabal hando como tropeiros, mensageiros, campeiros, na fabricação de pólvora e nas plantações de fumo e erva-mate cultivadas pel os rebeldes (Leitman, 1997, p. 69, nota 28).

$\mathrm{N}$ a madrugada de 14 de novembro de 1844 , no Cerro de Porongos, então município de Piratini, atualmente pertencente à cidade de Pinheiro Machado, ao sul do estado do Rio Grande do Sul, parte de um dos corpos de lanceiros negros foi dizimada pelas tropas imperiais. Esse episódio recebeu diversas denominações: "Surpresa", "B atal ha", "M assacre" ou, ainda, "Traição de Porongos". A morte dos guerreiros negros nesse evento gerou uma acal orada controvérsia entre os historiadores e estudiosos que se debruçaram sobre o tema da Revolução Farroupilha que tem continuidade até os dias de hoje.

Um primeiro grupo defende a tese de que o comandante do destacamento de negros em questão, o general farroupilha D avid Canabarro, teria desarmado e separado os lanceiros do restante das tropas acampadas nas imediações do Cerro de Porongos para que fossem aniquilados pelo exército imperial sem oferecer resistência. Ele teria feito um acordo com o líder imperial Barão de Caxias objetivando livrar-se 
dos soldados negros para facilitar a assinatura do tratado de paz que vinha sendo negociado. o Império do Brasil mostrava-se contrário à idéia de premiar com liberdade os escravos insurretos. A lém disso, parcelas da elite gaúcha temiam a possibilidade de que esses negros politizados e militarizados pudessem se somar a outros em al gum levante contra a ordem vigente. 0 indício que corrobora essa tese é a existência de uma carta remetida pelo Barão de Caxias para o coronel Francisco Pedro de Abreu, comandante da força imperial que atacou os lanceiros em Porongos. Esse enfoque interpretativo vê esse episódio como uma traição do general farrapo aos sol dados negros a ele subordinados. Essa posição é adotada na atualidade por alguns pesquisadores e por integrantes do movimento negro.

Por outro lado, um segundo grupo de estudiosos defende que a citada carta teria sido forjada pelos imperiais com o intuito de desmoralizar David Canabarro e criar cisões entre os farrapos. Nessa perspectiva, 0 assassinato dos lanceiros negros teria sido uma surpresa e não uma traição, já que teriam sido pegos desprevenidos. Tal enfoque é adotado principalmente pelos tradicionalistas.

Embora o movimento tradicionalista tenha se apropriado da questão dos lanceiros negros há bastante tempo, ${ }^{4}$ somente nos úl timos anos 0 $M$ assacre de Porongos voltou a ser discutido de forma mais evidente, não apenas por historiadores e estudiosos da R evolução F arroupilha, ${ }^{5}$ mas por negros que buscam o reconhecimento da participação de seus antepassados, como protagonistas, da constituição do Rio G rande do Sul e de momentos cruciais de sua história. ${ }^{6}$

Integrantes do movimento negro pressionaram o Estado em seus diferentes níveis

\footnotetext{
4. Entre as entidades ligadas ao M ovimento Tradicionalista Gaúcho encontramos quatorze que utilizam a palavra lanceiros em sua denominação. 0 movimento tradicionalista colocou um marco em homenagem aos "bravos farrapos" à beira da estrada dos Cerros de Porongos em 1983, em um projeto de levar a chama crioula a diversos pontos do estado significativos para os gaúchos. Em 1996, um piquete do município de Pinheiro Machado apresentou no desfile de 20 de setembro o tema dos lanceiros negros, causando surpresa e curiosidade no público.

5. Vide como exemplo FLORES, Moacyr. Negros na Revolução Farroupilha. Traição em Porongos e farsa em Ponche Verde. Porto Alegre: EST Edições, 2004.
}

administrativos (federal, estadual e municipal) para que ele promovesse políticas públicas em relação ao tema. Desde 2003, está em andamento o processo de constituição de um memorial aos lanceiros negros em área do Cerro de Porongos promovido pela Prefeitura M unicipal de Pinheiro $M$ achado, em parceria com o governo estadual e contando com o apoio da Fundação Cultural Palmares, ligada ao Ministério da Cultura. Embora o referido memorial venha a ser edificado no município de Pinheiro M achado, esse fato mobiliza pessoas de outras cidades do $\mathrm{R}$ io $\mathrm{G}$ rande do Sul. A té mesmo porque a idéia de construí-lo partiu inicialmente de um grupo de integrantes do movimento negro de Guaíba, município da região metropolitana de Porto A legre. Foram eles que, no ano de 2002, procuraram a administração da referida cidade para apresentar o projeto, que não foi, ao menos naquele momento, levado adiante. Posteriormente, no ano de 2003, em função da visibilidade nacional que produções cinematográficas deram ao tema, os governos municipal e estadual retomaram a idéia e buscaram parceria com 0 governo federal e a sociedade civil para concretizá-la. Constituiu-se um grupo de discussão para a viabilização do projeto e, a partir de então, foram realizadas diversas atividades sobre 0 tema. Dentre elas, destacam-se seminários e celebrações no dia 14 de novembro (data provável do massacre dos lancei ros negros) na cidade de Pinheiro $M$ achado. A prefeitura do município comprou uma área junto ao Cerro de Porongos de três hectares para a construção do memorial. $\mathrm{No}$ ano de 2004, foi colocada uma pedra que servirá de base à futura edificação e publicado um protocolo de intenções para a realização de um concurso nacional para a escolha do artista que a produzirá. Cabe sal ientar que, nos últimos dois anos, as celebrações do 14 de novembro no município de Pinheiro $M$ achado contam com a presença de negros de várias partes do Rio

\footnotetext{
6. É importante lembrar também que o tema obteve visibilidade nacional por meio de produções cinematográficas como o filme Netto perde sua alma, dirigido por B eto Souza e Tabajara Ruas, lançado em 2001, e a minissérie da TV Globo A casa das 7 mulheres, baseada no romance homônimo de Letícia Wierzchowski, dirigida por Jayme Monjardim e $M$ arcos Schechtmann e exibida entre 7 de janeiro e 8 de abril de 2003.
} 
Grande do Sul. ${ }^{7}$ D urante esse período, em municípios como Caçapava do Sul e Porto A legre, foram erigidas placas em homenagem aos lanceiros negros.

Em nível federal, o Instituto de Patrimônio Histórico e A rtístico Nacional (Iphan), também ligado ao M inistério da Cultura, está realizando desde 2004 um inventário de referências culturais sobre o tema para o eventual registro deste como patrimônio imaterial. Fui convidada, como antropóloga, a compor a equipe de pesquisa que realizou a etapa de levantamento preliminar do inventário sobre o M assacre de Porongos.

E ssas ações do poder público foram iniciadas em virtude da mobilização política do movimento negro, mas também em decorrência de um contexto político mais amplo, no qual se afirmam a questão identitária e o reconhecimento da diversidade. R eferimo-nos a um processo que se intensificou a partir dos debates da Constituição de 1988 e que implicou mudanças no regime de visibilidade da etnicidade brasileira, deuma situação de invisibilidade ${ }^{8}$ para uma crescente hi pervisibilização das diferenças. A incorporação da multiculturalidade por meio de leis e políticas de Estado ${ }^{9}$ se fez acompanhar de programas e linhas de financiamento de agências internacionais para a promoção de grupos tradicionalmente excluídos. ${ }^{10} 0$ discurso assimilacionista de outrora que buscava tornar os étnicos nacionais, os diferentes iguais, é substituído na atualidade por outro em que se discutem mecanismos de garantia de direitos e

7. A celebração ocorrida em 14 de novembro de 2004 contou com a participação de mais de três mil negros oriundos dos municípios de Cachoeira do Sul, Caxias, Guaíba, Pelotas, Piratini, Porto Alegre, Rio Grande, São Lourenço, entre outros.

8. A invisibilidade pode ocorrer no âmbito individual, cole tivo, nas ações institucionais, oficiais e nos textos científicos. Não implica dizer que a diversidade não é vista, mas que é tida como inexistente. Trata-se de um mecanismo de negação do outro, muitas vezes inconsciente, que produz e reproduz a discriminação e o preconceito (Leite, 1996).

9. Refiro-me ao Artigo 68 do A to de Disposições Constitucionais Transitórias da Constituição Federal de 1988: "A os remanescentes das Comunidades dos Quilombos que estejam ocupando as suas terras é reconhecida a propriedade definitiva, devendo o Estado emitir-Ihes os respectivos títulos".

10. Vide o exemplo da atuação da Fundação Ford no Brasil nos últimos anos. exercício da cidadania com base na alteridade, do reconhecimento da existência de grupos étnicos diferenciados.

Como membro da equipe de pesquisa do Inventário sobre o M assacre de Porongos tive a oportunidade de conversar com várias pessoas envolvidas no processo de discussão para a construção do memorial em homenagem aos lanceiros negros e identificar um contexto de disputas simbólicas em torno dessa figura de forma bastante similar ao observado por B rum (2004) em relação ao personagem de Sepé Tiarajú. Trata-se de um campo de interlocução ${ }^{11}$ regional onde diferentes atores sociais (movimento negro, movimento tradicionalista, pesquisadores, políticos, entre outros) debatem e produzem narrativas sobre o tema.

\section{O contexto local}

Com a emancipação de Pedras Altas em 1996, antigo distrito da cidade onde se localiza o castel o da Granja Pedras A Itas, construído por J oaquim Francisco de $\mathrm{A}$ ssis $\mathrm{B}$ rasil, ${ }^{12}$ o município de Pinheiro $M$ achado perdeu uma de suas principais atrações turísticas. ${ }^{13} \mathrm{~A}$ construção de uma edificação em referência aos lanceiros negros possibilitaria à cidade pleitear sua inclusão na Rota Farroupilha. ${ }^{14} \mathrm{~A}$ importância que 0

11. Segundo Grimson ( $s / d$ ), um campo de interlocução é um espaço social e simbólico no qual um conjunto de atores interage e, portanto, reconhece nos outros - incluindo seus adversários ou inimigos - um interlocutor necessário. 0 conceito pode aplicar-se a níveis globais, regionais ou nacionais, entre outros.

12. A ssis Brasil ergueu a fortaleza com traços medievais em uma das paisagens mais isoladas do Rio Grande do Sul para mostrar que era possível desfrutar a natureza sem ficar embrutecido. A idéia não era ostentar, mas enobrecer 0 campo. 0 diplomata, que privou com reis e chefes de Estado, achava que 0 arado e o livro eram as ferramentas do progresso. Em 1999, o governo tentou tombar o castelo de Pedras Altas como monumento histórico, mas os descendentes de Assis Brasil recusaram, preferindo manter 0 castelo com a família.

13. Entre as atrações turísticas do município de Pinheiro $M$ achado, o grande destaque é a realização da Comparsa da Canção Nativa, considerado um dos maiores festivais de música nativista do estado. É realizado anualmente no último final de semana de janeiro, durante a realização da Feira e Festa Estadual da Ovelha (Feovelha), também considerado um dos maiores eventos do gênero em nível nacional.

14. Cinco cidades estão envolvidas na implantação da Rota Farroupilha: Alegrete, Candiota, Piratini, Caçapava do Sul e Dom Pedrito. Participaram prefeitos, secretários de Tu- 
desenvolvimento do turismo adquire nesse contexto só pode ser compreendida ao passo que fornecemos ao leitor maiores informações sobre o município em questão. Ele localiza-se na metade sul do estado do Rio Grande do Sul, região que tem uma história de estagnação e decadência econômica. ${ }^{15}$ Pinheiro $M$ achado possui uma área de $2.227,9 \mathrm{~km}^{2}$ e conta com uma população de 14.134 habitantes. Com uma densidade de seis habitantes por $\mathrm{km}^{2}, 72 \%$ de sua população é urbana. Fica a aproximadamente $370 \mathrm{~km}$ da capital. 0 clima predominante é 0 frio, com média de temperatura anual entre $2^{\circ} \mathrm{C}$ e $18^{\circ} \mathrm{C}$. 0 solo caracteriza-se por ser raso e

rismo, agentes, operadores e guias turísticos, além dos donos das propriedades que estão trabalhando com o turismo rural na região, buscando resgatar a cultura e as tradições gaúchas. A Rota Farroupilha coloca em evidência uma parte importante do passado do RS, recheado de heróis, prédios históricos, trilhas e muitas lembranças. Em Candiota, foi proclamada a República Riograndense; Piratini, Caçapava do Sul e A legrete foram as capitais revolucionárias; Dom Pedrito detém o título de Capital da Paz, por ter consumado, nas coxilhas do Poncho Verde, o fim do conflito entre os republicanos farroupilhas e o governo imperial. Outro projeto turístico desta monta é a "Rota Caminho Farroupilha", parte do Projeto Turismo na Costa Doce, que divulga e promove as rotas turísticas situadas junto ao Rio Guaíba e às Lagoas M angueira e dos Patos. Começando por Guaíba, na Região M etropolitana, local onde morreu Bento Gonçalves, o passeio continua pela cidade de Cristal, onde existe uma réplica da casa do herói da R evolução Farroupilha. Depois, a visitação segue por Camaquã, que abriga o túmulo da esposa de B ento Gonçalves, Caetana. Em São Lourenço do Sul, os visitantes podem visitar estaleiros, onde são fabricados barcos para todo 0 estado, e também conhecer um pouco da história do aguerrido Giuseppe Garibaldi e seu envolvimento com a questão náutica na revolução. Shows e dramatizações também fazem parte da aventura. Em Pelotas, 0 aspecto econômico do movimento toma forma durante a visitação à "Rota da Charqueada", que compreende sete charqueadas dentro do Arroio Pelotas, onde também é possivel conhecer um pouco sobre a história da participação dos negros nesse episódio, pelas encenações apresentadas na Charqueada São João. Já em Piratini, cidade onde se situava a administração da República Rio-grandense, os espetáculos são promovidos nas ruas e em diversos prédios, onde 0 turista pode sentir-se parte da história. Para encerrar a peregrinação, no caminho entre Rio Grande e São J osé do Norte, os "navegadores da história" podem fazer um passeio no barco-museu Cuter Minuano (réplica do barco Seival de Garibaldi) e também visitar o local onde se encontram os restos mortais de $B$ ento Gonçalves. Os turistas podem fazer toda a rota ou escolher determinados pontos para visitar. As operadoras dessa rota são a Caminhos do Sul, a Rota Cultural e a Unesul Turismo.

15. Sobre este assunto ver ILHA, A dair Silva; ALVES, Fabiano Dutra e SARAIVA, Luis Heitor Barboza. Desigualdades regionais no RS: 0 caso da metade sul. Texto disponível em http//www.fee.tche.br/sitefee/douwload/eeg/1/mesa 3_ilha_alves_saraiva_pdf. com a presença de aflorações de rochas com grande quantidade de calcário, considerado de excelente qualidade. 0 relevo é bastante irregular, destacando-se a Serra do Passarinho, a Serra do Velleda e a Serra das A sperezas. Também se percebe a formação de inúmeros cerros, especialmente no $2^{\circ}$ Distrito, onde se localiza 0 de Porongos. Tem um grande número de riachos e sangas. A economia é baseada principalmente na agricultura, na pecuária, na extração de pedras para exportação e pedras de revestimento e na produção de cimento. O utro destaque é a viticultura, que, devido à característica do clima da serra do sudeste, favorece a elaboração de vinhos finos de alta qualidade. Essa atividade começou a ser implementada em algumas propriedades da cidade nos últimos anos, com o objetivo de se tornar uma al ternativa mais lucrativa à agricultura e à pecuária tradicionais da região. 0 extrativismo mineral, por sua vez, gera poucos recursos em termos locais. Desse modo, o desenvolvimento do turismo se apresenta como uma atividade bastante atraente para a geração de emprego e renda no município.

As relações sociais entre brancos e negros nessa localidade são fortemente marcadas pela segregação social dos primeiros em relação aos últimos. Existem dois clubes criados por negros em razão da impossibilidade de freqüentarem os demais por causa da sua raça/cor: a Sociedade Recreativa U nião Democrata e a Sociedade Recreativa e Cultural Filhos da Lua. São inúmeros os relatos de situações de preconceito e discriminação vividas por eles na cidade. Desde bailes separados por cordas até cortejos de rainhas de carnaval brancas que os foliões negros só podiam escoltar até a porta dos clubes onde não podiam entrar. Em Pinheiro M achado, existe uma organização do movimento negro desde a década de 1990 formada por pessoas que tinham al guma vivência em outros municípios, até mesmo na capital.

\section{0 evento que marcou os 160 de Porongos}

Pode ser observado de forma mais intensa o processo de disputa simbólica em torno da figura dos lanceiros negros num evento deno- 
minado Nossos heróis não morreram - 160 anos de Porongos, nos dias 13 e 14 de novembro de 2004, no município de Pinheiro M achado/RS. Este foi organizado pela Comissão Memorial Lanceiros Negros - composta pelo M inistério da Cultura/Fundação Cultural Palmares, governo do Estado/Secretaria da Cultura, Prefeitura Municipal de Pinheiro Machado, M ovimento N egro U nificado, entre outras entidades. A programação foi a seguinte:

Dia 13/11/2004.

A to Solene de A bertura.

Local: Teatro M unicipal de Pinheiro M achado.

H orário: $18 \mathrm{~h}$.

A tividades Culturais: G rupo de Teatro Tropeiros dos Sonhos, Grupo de Dança Liberdade de Expressão, Grupo de Dança 100\% Hip Hop, A ssociação de Capoeira Filhos da Roda.

Horário: $19 \mathrm{~h}$

Espetáculo de música e dança Lanceiros Negros. A rtistas: L oma, Sirmar A ntunes, Gel e Cia de D ança, Raízes D Á frica.

Horário: 20h30.

A tividades A rtísticas: Grupo de Teatro Tropeiros do Sonho, G rupo de Pagode Tempero do Samba, Grupo de Pagode Nosso J eito, Grupo de Pagode Quilombolas do RJ.

Local: Praça M unicipal de Pinheiro M achado.

Horário: $22 \mathrm{~h} 30$.

Vigília: Toque de Tambor Afro. Recepção aos

Cavaleiros de Porto A legree CTG Lila A Ives.

Local: Praça M unicipal de Pinheiro M achado.

Horário: 1 h

Recital Poético com Sirmar A ntunes.

Horário: 2h.

Dia 14/11/2004

Local: Cerro de Porongos - M unicípio de Pinheiro $M$ achado.

A bertura de "Caminhos" por lalorixás.

Horário: 9 h

Leitura de Documento da Comissão Pró-M emorial $L$ anceiros $\mathrm{N}$ egros.

Horário: 9h15.

A presentação Grupo Teatral de Pinheiro M achado. Horário: 9h30.

A presentação de G rupo Temático Ponto $Z$.

Horário: $10 \mathrm{~h}$.

A presentação Grupo Quilombolas RJ . Horário: 10 h30.
A to de A bertura: L ançamento da Pedra Fundamental do M emorial L anceiros $N$ egros.

Horário: 11h.

Leitura da Carta de Duque de Caxias a Canabarro. A ssinatura de Protocolo de Intenções para E dital de Concurso Público Pró-M emorial. A presentações: Poema "Carga de L ança”, recitado por Sirmar A ntunes. Toque de Tambor com a chegada dos $C$ aval eiros L anceiros N egros. Toque de Clarim.

A Imoço afro na cidade de Pinheiro $M$ achado.

Horário: $14 \mathrm{~h}$

Recital de Poesia, com Liliana Cardoso. A presentação do Grupo Teatral de Encruzilhada do Sul.

Para fins de análise, não descreverei de forma cronológica o desenrolar dos fatos, mas sim em virtude das possíveis interpretações que me proponho a fazer sobre o significado deles.

No final da tarde do dia 13, no Teatro M unicipal Ludovico Pórzio, ocorreu uma solenidade de abertura na qual estavam presentes representantes do governo municipal, estadual, federal, do I phan, do movimento negro, entre outros. As autoridades falaram algumas palavras sobre os lanceiros negros e a importância da construção do memorial para uma platéia de aproximadamente quinhentas pessoas oriundas da própria localidade e de entidades do movimento negro de outras cidades.

0 prefeito Carlos Ernesto Betiollo e o secretário de Indústria, Comércio e Turismo do município, Paulo Ricardo Javiel Rezende, referiram-se à $B$ atal ha de Porongos como um "evento". Nas palavras do prefeito, a questão dos lanceiros negros tornou-se um projeto social, cultural e turístico. ${ }^{16} 0$ representante da Secretaria de Cultura do Estado, M anoel Claúdio $B$ orba, disse que esperava que o resgate dessa história permitisse a verdadeira integração do Rio G rande do Sul, uma vez que, antes de sermos desta ou daquela raça, éramos gaúchos. A posição desses políticos de diferentes esferas

16. Em todos os eventos oficiais sobre o tema, os políticos locais evitam se posicionar sobre o caráter do episódio histórico - se surpresa ou traição -, reafirmando a importância de seu resgate para o município como um todo. Como já foi mencionado anteriormente, a administração municipal de Pinheiro $M$ achado adquiriu três hectares nas proximidades do Cerro de Porongos para a construção do memorial. A lém disso, ela colocou placas de sinalização ao longo do percurso que leva até o local. 0 prefeito está construindo com recursos próprios um hotel na cidade. 
(municipal e estadual) reflete 0 interesse pela exploração turística de um fato histórico sem que isso implique discutir o que tal evento significou ou passa a significar para os negros do RS ou de que forma ele se relaciona com 0 contexto das relações interétnicas em nosso estado. Como foi explicado anteriormente, há um conjunto de fatores que tornam o desenvolvimento do turismo uma questão muito atraente para a cidade de Pinheiro $M$ achado. 0 destaque que se dá à identidade gaúcha como algo primordial, mais importante que outras identidades sociais, remete a uma figura unificadora, homogênea, que se sobrepõe às diferenças sociais, econômicas, culturais e étnicas.

A o fim dos discursos, uma representante do movimento negro local, R osa Claudete Vaz Duarte, cantou o hino riograndense, ${ }^{17}$ mas com al gumas alterações. No verso que diz "povo que não tem virtude acaba por ser escravo", ela cantou "povo que não tem virtude acaba matando escravo". Em outro momento do evento, atores e dançarinos encenaram a peça Lanceiros negros, dirigidos por Ney Ortiz, ${ }^{18}$ com a participação especial de Sirmar A ntunes. ${ }^{19}$ Entre as músicas do espetáculo, mais uma vez o hino riograndense é interpretado por uma mulher negra. Desta vez, a expressão "povo que não tem virtude acaba por ser escravo" é substituída por "povo que é lança e virtude a clava quer ver escravo". Na solenidade de abertura do evento, na manhã do dia 14, essa mesma performance pôde ser observada. A alteração dessa estrofe do hino muda o sentido da palavra escravo de uma condição em que se chega pela falta de virtude para a de possuidor dessa qualidade que é vítima daquel es que não a têm. Ela também remete ao evento em que os lanceiros negros foram mortos e ao caráter daquel es que foram os responsáveis por tal ato. Essas

17. 0 hino farroupilha foi elevado a hino do Rio Grande do Sul por uma lei estadual de 1966, como parte de um processo de expansão do tradicionalismo junto ao poder público, que colaborou em muito para oficializar a ideologia do movimento (vide Oliven, 1991, e M aciel,1999).

18. A rtista plástico negro, fundador do grupo cultural Raízes da África, e residente em Porto Alegre (RS).

19. A tor negro gaúcho, ficou nacionalmente conhecido por sua atuação no filme Netto perde sua alma, no qual interpretou o sargento Caldeira, integrante do corpo de lanceiros negros durante a Revolução Farroupilha. mudanças na execução do hino demonstram que o processo de construção do memorial aos lanceiros negros constitui um momento privilegiado para que atores sociais historicamente marginalizados - como os negros e, dentre eles, nesse caso, as mul heres negras - tentem inscrever performativamente contracoerências - sobre o fim dos lanceiros negros e sobre os próprios negros - na narrativa dominante sobre a história do Rio G rande do Sul. Dessa forma, através de suas performances, as mulheres negras desvelam o caráter ideológico da história oficial de nosso estado, subvertendo os sentidos atribuídos à escravidão e ao extermínio dos soldados negros (vide B habha, 1998).

$\mathrm{Na}$ encenação da peça Lanceiros negros, na noite do dia 13, diversos elementos foram associados às suas figuras: a religiosidade africana, a musicalidade e a própria Á frica. Eles foram representados como combatentes seminus, descalços, com lanças em punho, guerreando ao som do batuque. A s correlações com o continente africano não pararam por aí. No dia 14 pela manhã, distante $27 \mathrm{~km}$ do centro de Pinheiro M achado ejunto ao Cerro de Porongos, foi inaugurada a pedra fundamental no local onde deverá ser construído o memorial aos lanceiros negros. N ela foi gravado um poema que transcrevo a seguir:

Ancestralidade

Ouço no vento

O soluço do arbusto.

É o sopro dos antepassados.

N ossos mortos não partiram,

Estão na densa sombra.

Os mortos não estão sob a terra.

Estão na árvore que se agita,

Na madeira que geme,

Estão na água que geme,

Estão na água que flui,

$\mathrm{N}$ a água que dorme,

Estão na cabana, na multidão.

Os mortos não morreram.

N ossos mortos não partiram.

Estão no ventre da mulher,

No vagido do bebê e no tronco que queima.

Os mortos não estão sob a terra,

Estão no fogo que se apaga,

$\mathrm{N}$ as plantas que choram,

$\mathrm{N}$ a rocha que geme, 
Estão na floresta,

Estão na casa.

N ossos mortos não morreram.

$$
\begin{aligned}
& \text { BIRAgo Diop } \\
& \text { Poeta africano }
\end{aligned}
$$

A o final da solenidade, os participantes eram esperados na sede do município para um almoço "africano", preparado por um chef de cozinha baiano trazido pela representante da Fundação Cultural Palmares, M aria Bernadete Lopes. A utilização de elementos referentes à religiosidade, à musicalidade e ao continente africano se fazem valer de um imaginário social que povoa a mente de brasileiros e também de gaúchos sobre os negros, seu local de origem e aquilo que lhes caracteriza como grupo cultural. A inda que tentem transformar a narrativa dominante, eles têm que, para se fazerem inteligíveis, apelar a al guns elementos dela.

$\mathrm{N}$ a noite de 13 de novembro, seguiram-se apresentações de grupos de dança, música e capoeira da própria local idade que evocaram a figura de Zumbi dos Palmares em suas performances. Pela manhã do dia 14, na solenidade de abertura, diversas autoridades falaram. Dentre elas, Vanda M aria M enezes Barbosa, secretária de Estado da Mulher de A lagoas, trazida por M aria Bernadete Lopes, da Fundação Cultural Palmares. ${ }^{20}$ Ela traçou uma comparação entre os lancei ros negros e Zumbi dos Palmares. Segundo Vanda, ambos lutaram pela sua liberdade, foram traídos e mortos. No seu ponto de vista, além da construção do memorial, ruas e praças que tivessem o nome de $D$ avid Canabarro deveriam ser renomeadas com a denominação "Ianceiros negros", em um claro sinal de reconhecimento da importância que estes tiveram para a R evolução Farroupilha e a história do R io Grande do Sul. A correlação entre as figuras dos lanceiros negros e a de Zumbi apresenta-se como um argumento por parte do movimento negro e de seus representantes dentro da máquina estatal para justificar o reconhecimento dos primeiros em nível de Estado. Eles têm uma trajetória marcada por fatos que Ihes possibilitam serem considerados

20. As duas são mulheres profundamente engajadas no movimento negro. heróis: luta pela liberdade, traição e morte. A lém disso, o resgate de sua história e importância parte da mesma região do B rasil. $\mathrm{N}$ a década de 1980, integrantes do M ovimento N egro U nificado gaúcho conceberam a idéia de retomar a figura de Zumbi dos Palmares. Esse personagem histórico ficou conhecido e tornou-se reconhecido em todo o país ao longo dos anos, inclusive no R io de J aneiro, onde o dia 20 de novembro, provável data da sua morte, tornou-se feriado estadual há poucos anos.

$\mathrm{Na}$ manhã do dia 14 , junto ao Cerro de Porongos, aproximadamente quinze ônibus e dezenas de carros estavam estacionados na entrada da propriedade da família A Ivarez, de onde foram adquiridos os hectares para a construção do memorial. U ma lona de circo fora montada e um palanque erguido próximo à casa dos donos daquela área. $V$ árias faixas das organizações do movimento negro ali presentes estavam amarradas à estrutura da lona e às cercas de arame próximas. Muitas pessoas circulavam pelo local. Para o início da solenidade, a programação era de que os pais e mãesde-santo do município de Pinheiro Machado fariam a abertura dos caminhos, mas a presença do bispo de Bagé, dom Gilio Felício, ${ }^{21}$ no palanque alterou o protocolo. Ele acabou por proferir uma oração, em caráter ecumênico, mas os representantes dos terreiros e casas de santo permaneceram em silêncio de costas para 0 bispo e de frente para o público, visivelmente constrangidos. A disputa religiosa que se trava em torno da figura dos lanceiros ficou evidente. Como a história desses sol dados ainda está por ser escrita, suas figuras podem ser apropriadas tanto pela I greja Católica quanto pelos cultos afro-brasileiros.

Próximo às duas horas da madrugada do dia 14, horário em que se acredita tenha ocorrido a morte dos lanceiros negros, foram disparados oitenta fogos de artifício como forma de homenageá-los. Antes, contudo, Sirmar A ntunes e

21. Nascido em Lajeado (RS), foi vigário em Santa Cruz do Sul (RS). Ele é hoje um dos seis bispos negros no Brasil, em um universo de quatrocentos. Em 1998, foi enviado para a Bahia como bispo de Cruz das Almas, no Recôncavo Baiano, e, com sua iniciativa de promover um diálogo inter-religioso entre católicos e cultos afros, tornou-se nacionalmente conhecido. 
Ney Ortiz, visivel mente alterados pela ingestão de bebidas alcóolicas, discursaram do al to da sacada do teatro municipal para al gumas dezenas de pessoas que permaneceram em vigília à espera do espetáculo pirotécnico. Eles falaram explicitamente sobre a traição de Canabarro e da obrigação que os tradicionalistas tinham de pedir perdão aos negros gaúchos por cultuarem tal figura. Entre a platéia que assistia, estavam os representantes do poder público municipal que se mostravam contrariados com tais declarações, principalmente aqueles que dentre eles faziam parte de entidades tradicionalistas. A lguns dias depois, em um site do município de Pinheiro $M$ achado, encontramos o seguinte comentário de L uiz Henrique Chagas da Silva, secretário de Administração da cidade, que acompanhou todo o evento:

\section{Os Homens de Preto.}

Nos dias 13 e 14 de novembro, mais precisamente no final do dia 13 e na manhã do dia 14, Pinheiro $M$ achado viveu um importante momento histórico, eis que aqui foi realizado um grande evento alusivo aos 160 anos do E pisódio dos Porongos. Pelo que fomos informados, dezessete ônibus estavam estacionados junto ao Cerro dos Porongos. Realmente uma atividade cultural intensa, com pronunciamentos bem colocados, outros nem tanto carregados de ideologia política - culminando com descerramento da placa na pedra fundamental e assinatura do Protocolo que autoriza a abertura de Concurso Público Federal visando à construção do $\mathrm{M}$ emorial ao L anceiro N egro. Tivemos importantes colocações, porém outras que além de carregadas de desconhecimento da nossa história e da nossa cultura, como a que exigia que todos os logradouros públicos que levassem o nome de David Canabarro fossem substituídos, como se não tenha sido - General um grande defensor da causa Farroupilha e um bravo guerreiro, como se fosse possível acreditar que a Carta de Caxias indiscutivelmente não foi forjada. Convenhamos!!! Comungo da tese de que os negros não lutaram por um ideal que não fosse a alforria, a liberdade; que não tinham tratamento igual aos demais "soldados"; que foram traídos nesta essência, mas não posso partilhar da idéia de que tudo na Revolução Farroupilha tenha sido traição e mentira como aqui foi plantado, ou então seria um idiota quando fui patrão de
Centro de Tradições $G$ aúchas por dois anos. Temos, sim, que ter em nossas ruas, avenidas, logradouros públicos os nomes dos nossos heróis farrapos; dos nossos políticos como Getúlio Vargas e outros, que, pela coragem e pel a competência, fizeram deste Estado um dos mais respeitados da $\mathrm{N}$ ação $\mathrm{B}$ rasileira. ${ }^{22}$

A posição do artigo expressa a insatisfação dos tradicional istas com o teor das declarações proferidas por integrantes do movimento negro ou por seus representantes na esfera estatal. Como foi dito no início do texto, a Revolução Farroupilha é um dos principais el ementos que compõem o imaginário sobre a figura do gaúcho. Colocar em discussão o seu caráter ou o de seus heróis representa uma afronta à tradição e ao próprio movimento. A lém disso, aceitar a idéia de uma traição implica assumir que o preconceito fazia e ainda faz parte da sociedade gaúcha e que as relações entre brancos e negros não são pautadas pel os ideais liberais, progressistas e democráticos atribuídos ao movimento farroupilha. No entanto, ao mesmo tempo em que al guns negros atacam a figura de David Canabarro, outros se apropriam do tradicional ismo, como ilustra o momento da madrugada do dia 14 , em que dois negros a cavalo e devidamente pichados entregaram uma placa aos representantes do movimento negro local. Eles eram de um piquete de Porto A legre criado recentemente e que se denomina L anceiros N egros.

Como o leitor pode observar, ao longo do texto o processo de construção do memorial aos lancei ros negros apresenta várias categorias em ação. Dentre elas, destacamos as de gaúcho e negro. A o colocá-las em prática num evento como o que descrevemos, corre-se o risco que elas tenham as estruturas de significados que normalmente lhe são impostas subvertidas. Dessa forma, diversos atores sociais - políticos, integrantes do movimento negro, tradicional istas, entre outros - disputam seus sentidos em uma verdadei ra luta si mbólica na qual o que está em jogo é o poder de definir o que venham a ser tais categorias em termos conceituais (Sahlins, 2003). Se, para os tradicional istas e para muitos políticos, a categoria negro deve ser engl obada

$\overline{22 .}$ Coluna de 26 de novembro de 2004, disponível em http//www.pinheironline.com.br. 
pela de gaúcho, para os integrantes do movimento negro as duas não se excluem e até mesmo podem se complementar, isto é, gaúcho também é negro e vice-versa, em um processo no qual nossa identidade regional enegrece e a identidade étnica desse grupo se agaúcha, o que nos possibilita pensá-las de forma mais plural.

\begin{abstract}
A bstract: Taking as universe empirical a event on behalf of building the one memorial in honour at black lancers in the Pinheiro Machado city (RS), I undertake for the symbolic disputes what is happening around this figures. I look for to demonstrate what the differents appropriations the one historic experience in cormom - the Massacre of the Porongos - have conections with the configuration of the etnical and regional identitys and with the relations between differents social groups what made up the state of the Rio Grande do Sul.
\end{abstract}

K ey-words: black lancers; etnical identity; regional identity.

\section{Referências}

BA RCELLOS, Daisy M acedo de. F amília e ascensão social de negros em Porto Alegre. 1996. Rio de J aneiro, Tese (D outorado em A ntropologia) - M useu Nacional, UFRJ.

Dante de L aytano e o folclore no Rio G rande do Sul. Horizontes Antropológicos, n. 12. Porto A legre: PPGAS, 1997.

BHABHA, Homi K. O local da cultura. Tradução de M yriam Á vila, Eliana Lourenço de L ima Reis e Glaúcia Renate Gonçalves. Belo Horizonte: Ed. UFM G, 1998.

BRUM, Ceres Karam. "Esta terra tem dono". Disputas de representação sobre o passado missioneiro no Rio Grande do Sul: a figura deSepéTiarajú. M anuscrito, 2004, 29 pp.

CARRION, Raul. Os lanceiros negros na Revolução F arroupilha. Porto A legre: Gabinete do Vereador Raul Carrion, 2003.
FL ORES, M oacyr. A Revolução F arroupilha. Porto A legre: Ed. da UFRGS, 2004.

N egros na Revolução F arroupilha. Traição em Porongos e farsa em Ponche Verde. Porto A legre, EST Edições, 2004.

GRIM SON, A lejandro. La nacion después del desconstructivismo. La experiencia argentina y sus fantasmas. Sociedad, n. 20-21, B uenos A ires, 2003.

. La etnicidade migrante. [s/d.]

ILHA, A dair Silva; ALVES, Fabiano Dutra e SARAIVA, Luis Heitor B arboza. D esigualdades regionais no RS: o caso da metade sul. Texto disponível em http// www.fee.tche.br/sitefee/ douwload/eeg/1/mesa_3_ilha_alves_saraiva_pdf.

LEITE, Ilka Boaventura (Org.). Negros no Sul do Brasil. Invisibilidade eterritorialidade. Florianópolis: L etras Contemporâneas, 1996.

LEITM AN, Spencer. Negros farrapos: hipocrisia racial no sul do B rasil no século XIX. In: DACANAL, J osé Hildebrando (Org.). A R evolução F arroupilha: história e interpretação. Porto A legre: M ercado A berto, 1997.

MACIEL, M aria Eunice de Souza. Considerações sobre gaúchos e colonos. Diversidade étnica e identidade gaúcha. Santa Cruz do Sul: Editora da Unisc, 1994.

- Tradição e tradicionalismo no Rio Grande do Sul. H umanas: Revista do Instituto de Filosofia e Ciências H umanas. Porto A legre, v. 22, n. 1/2, 1999.

OLIVEN, Ruben George. 0 nacional e o regional. Revista Brasileira de Ciências Sociais, n. 2, out. 1986.

0 maior movimento de cultura popular do mundo ocidental: o tradicional ismo gaúcho. Cadernos de Antropologia do Programa de Pós-G raduação em Antropologia Social, Porto A legre, n. 1, 1990.

Em busca do tempo perdido: o movimento tradicionalista gaúcho. Revista Brasileira de Ciências Sociais, n. 15, ano 6, fev. 1991.

SA HLINS, M arshall. Ilhas de história. Rio deJ aneiro: J orge Zahar, 2003. 